\title{
Air pollution aggravating COVID-19 lethality? Exploration in Asian cities using statistical models
}

\author{
Ankit Gupta ${ }^{1,2} \cdot$ Hemant Bherwani $^{1,2}$ (D) Sneha Gautam ${ }^{3}$. Saima Anjum¹ . \\ Kavya Musugu $^{1} \cdot$ Narendra Kumar $^{1} \cdot$ Avneesh Anshul $^{1} \cdot$ Rakesh Kumar $^{1,2}$
}

Received: 25 June 2020 / Accepted: 9 July 2020 / Published online: 15 July 2020

(c) Springer Nature B.V. 2020

\begin{abstract}
The present work estimates the increased risk of coronavirus disease (COVID-19) caused by severe acute respiratory syndrome coronavirus 2 by establishing the linkage between the mortality rate in the infected cases and the air pollution, specifically Particulate Matters (PM) with aerodynamic diameters $\leq 10 \mu \mathrm{m}$ and $\leq 2.5 \mu \mathrm{m}$. Data related to nine Asian cities are analyzed using statistical approaches, including the analysis of variance and regression model. The present work suggests that there exists a positive correlation between the level of air pollution of a region and the lethality related to COVID-19, indicating air pollution to be an elemental and concealed factor in aggravating the global burden of deaths related to COVID-19. Past exposures to high level of $\mathrm{PM}_{2.5}$ over a long period, is found to significantly correlate with present COVID-19 mortality per unit reported cases $(p<0.05)$ compared to $\mathrm{PM}_{10}$, with non-significant correlation $(p=0.118)$. The finding of the study can help government agencies, health ministries and policymakers globally to take proactive steps by promoting immunity-boosting supplements and appropriate masks to reduce the risks associated with COVID-19 in highly polluted areas.
\end{abstract}

Keywords COVID-19 $\cdot$ Coronavirus $\cdot$ Air pollution $\cdot \mathrm{PM}_{2.5} \cdot \mathrm{PM}_{10} \cdot$ Linear regression $\cdot$ SARS-CoV-2

\begin{tabular}{ll}
\multicolumn{2}{l}{ Abbreviations } \\
COVID-19 & Coronavirus disease 2019 \\
PM & Particulate matter \\
SARS & Severe acute respiratory syndrome \\
CoV & Coronavirus \\
UNPD & United Nations Development Programme \\
COPD & Chronic obstructive pulmonary disease \\
WHO & World Health Organisation
\end{tabular}

Hemant Bherwani

h.bherwani@neeri.res.in

1 CSIR-National Environmental Engineering Research Institute (NEERI), Nagpur, Maharashtra 440020, India

2 Academy of Scientific and Innovative Research (AcSIR), Ghaziabad, Uttar Pradesh 201002, India

3 Karunya Institute of Technology and Science, Coimbatore, Tamil Nadu 641114, India 


$\begin{array}{ll}\text { IEC } & \text { Information-education-communication } \\ \mu \mathrm{m} & \text { Micrometre } \\ Y & \text { Response variable } \\ m & \text { Slope } \\ X & \text { Model input variable } \\ C & \text { Model constant } \\ \varepsilon & \text { Model error } \\ \text { CI } & \text { Confidence interval } \\ R & \text { Regression } \\ \text { SE } & \text { Standard errors } \\ p & \text { Probability of extreme results of the statistical hypothesis test } \\ \text { DF } & \text { Number of independent variables in the regression model } \\ \text { SS } & \text { Mean regression sum of squares } \\ \text { MS } & \text { Mean error sum of squares } \\ F & \text { Ratio of the SS/MS } \\ \% & \text { Percentage }\end{array}$

\section{Introduction}

Air pollution is a front running cause for premature deaths globally (Balakrishnan et al. 2019; Cohen et al. 2017; Tong 2019; Nair et al. 2020). It affects human health in multiple ways. Some of the associated impacts are less severe, like respiratory infections, while others can be as deadly as lung cancer, strokes, and chronic obstructive pulmonary disorder (Balakrishnan et al. 2019; Cohen et al. 2017). Particulate matter (PM) contributes significantly to the global burden of air pollution-related diseases (Shamsipour et al. 2019; Anenberg et al. 2019); the PM can act as a carrier to transmit multiple infectious microorganisms, which have a serious impact on immunity, increasing susceptibility to varied diseases (Kim et al. 2018; Tong 2019; Wang et al. 2020a; Bherwani et al. 2020a). The present era of globalisation has expanded the limits of travel, business, lifestyle, industrial activities, and many others (Fenger 1999). People of urban areas are trying to persuade their lifestyle patterns to the global standards, thereby stressing an increased pace of human resource consumptions with rapid urbanisation (UNPD 2018). The ever-growing developmental activities are adding demands for more facilities, leading to increased activities in terms of on-road vehicles, residential complexes, and urban centres (Wang et al. 2020b). All these developments are continuously increasing the strain on natural assets like air, water, and land environments (Torrey 2004).

Nevertheless, the air is a vital element for the survival of all living beings; hence, it is necessary to keep it clean and safe. The anthropogenic activities are a major cause of ambient air pollution due to emission of many harmful pollutants in high concentration, which are health damaging (Gautam and Hens 2020a; Ghorani-Azam et al. 2016). Similarly, indoor air pollution is on the rise due to factors contributed by activities related to the use of the traditional ill-designed cook stove, refrigerators, biomass burning, poor ventilation, and surroundings (Gautam and Trivedi 2020; Nair et al., 2020; Gupta et al., 2020). Due to exposure of high air pollution concentrations, people are facing severe health effects. The associated health effects may be acute or chronic, depending upon pollutant concentrations, duration, and frequency of exposure (Dutheil et al. 2020; D'Amato et al. 2013). The most common diseases directly associated with ambient air pollution are heart disease, 
strokes, COPD, lung cancer, and acute respiratory infections in children (WHO 2018a). On the other hand, exposure to indoor air pollution may cause respiratory illness, cancer, eye irritation, musculoskeletal injuries, etc., both in children and in adults (Mishra 2003). One of the baseline effects of exposure to high air pollution concentrations is the compromised immune system of the human body (Rom et al. 2013; Lee et al. 2015).

Ambient air pollution is linked with an estimated 4.2 million premature deaths per year attributed to different chronic respiratory disorders, heart diseases, and lung cancer (WHO 2018 b). The majority of the world population are living in places where the air quality standards exceed the World Health Organisation (WHO) guideline values (WHO 2018c). Low-income cities with high population density are further severely impacted (WHO 2018d). In the Asia-Pacific region, 2.3 billion people are exposed to these high levels of air pollution, especially in China and India (Pawankar 2019). In India, for the year 2017, on an average 1320 number of casualties per million of the population were attributed to indoor and outdoor air pollution, whereas globally the average death rate for the same year was reported to be about 638 per million of the population (Gurjar et al. 2016). There are many air pollutants including but not limited to $\mathrm{PM}$ with diameters $\leq 10 \mu \mathrm{m}\left(\mathrm{PM}_{10}\right)$ and $2.5 \mu \mathrm{m}$ $\left(\mathrm{PM}_{2.5}\right)$, carbon monoxide, sulphur oxides, nitrogen oxides, tropospheric ozone, and volatile organic compounds which contribute to high human morbidities and mortalities (WHO 2006). Notice that PM is a major pollutant, responsible for respiratory infections, lung disease, COPD, and importantly compromised immune system (Kim et al. 2018). $\mathrm{PM}_{2.5}$, specifically, has an impact as it passes through the respiratory system and provides high chances of getting deposited in lungs (Kim et al. 2018; Li et al. 2018).

The recent outbreak of coronavirus disease, termed as COVID-19, has raised global concerns and led to total lockdown in many countries (WHO 2020a; Gautam and Trivedi 2020; Bherwani et al. 2020b; Wang et al. 2020a). The disease is caused by severe acute respiratory syndrome coronavirus 2 (SARS-CoV-2) (Gautam and Hens 2020b). Started in December 2019 from Wuhan City of China, the virus has now reached almost every country in the world (Gautam 2020a). This fatal and novel coronavirus is likely to spread rapidly in humans with close contact to already infected people (Cascella et al. 2020; Bherwani et al. 2020b). The spread of the virus may be contained by maintaining proper social distance, personal hygiene, avoiding gatherings, and visiting places like hospitals, meetings, and public transportations, which have a high risk of such virus contamination (WHO 2020b; Bherwani et al. 2020b; Gautam 2020b). Furthermore, the transmission of the virus has been reported through the air in the form of aerosols causing widespread mortality. The current study explores the hypothesis that the dwellers of highly polluted Asian cities, having a compromised immune system, may be more susceptible to mortality linked to novel coronavirus-infected cases. With this premise, we analyse the data in nine Asian cities, where data of air pollutants (i.e. $\mathrm{PM}_{2.5}$ and $\mathrm{PM}_{10}$ ) and COVID-19 cases are readily available.

\section{Methodology}

The WHO measures the annual mean concentration for air pollution and stipulates the guidelines for the annual mean concentration of PMs. These guideline values for $\mathrm{PM}_{2.5}$ and $\mathrm{PM}_{10}$ should not exceed an annual average of $10 \mu \mathrm{g} \mathrm{m}^{-3}$ and $20 \mu \mathrm{g} \mathrm{m}^{-3}$, respectively (WHO 2006). Select cities from WHO 2018 database, which are impacted by COVID-19 cases with readily available data, are selected for this work. Total of nine cities from Asia 
are studied, and the data matrix used for the selected cities is given in Table 1. As shown in the table, amongst the nine cities, four cities are from India, three from China, two from Pakistan, and one from Indonesia. The cities have been chosen based on the availability of data on COVID-19 cases and pollutants. Also, these cities have been less reported and studied w.r.t. COVID-19 links with air pollution and were not among the cities with the highest reported cases in the respective countries. These cities are amongst the top 500 most polluted cities in the world with respect to $\mathrm{PM}_{2.5}$ (CBS News 2017). The WHO database covers the data for ten years from 2007 to 2016, reporting annual mean values for the cities. As seen in the table, the average $\mathrm{PM}_{2.5}$ and $\mathrm{PM}_{10}$ exceed the WHO guidelines by severalfold, thereby impacting health. The percentage mortality per unit reported case is calculated in Table 1 by dividing the number of COVID-19-related deaths by the total number of reported cases as on 2 July 2020. This suggests that people in these regions have been continuously exposed to high pollution levels, which must have compromised their immune systems (Xing et al. 2016).

There have been many approaches used by various researchers to study the impact of air pollution on the compromised immune system of the people including remote sensing to analyse the spatiotemporal spread of air pollution, modelling to predict the concentration of air pollution vis-à-vis morbidity and mortality of individuals. Other primary approaches include clinical trials and dose-response studies. In the current study, we are using statistical tools to establish the relation. The pollution data for each city are analysed in relation to the number of deaths (mortality) per unit reported case. This normalisation (deaths per unit reported case) will factor out the clinical spread of the virus and only relate to the additional number of deaths related to other factors, mostly compromised immune system which has a direct relation to air pollution. The statistical analysis is performed on the data in Table 1 using a linear regression model to establish the relationship between air pollution parameters $\left(\mathrm{PM}_{2.5}\right.$ or $\mathrm{PM}_{10}$ concentrations) and the response variable (percentage mortality per unit reported cases). The analysis is performed using a single air pollution parameter at a time, as these air pollution parameters are neither mutually exclusive nor independent. The general linear regression model represented as a straight line as depicted by Eq. (1) (Montgomery et al. 2012):

Table 1 Data on air pollution level and COVID-19 cases in nine Asian cities

\begin{tabular}{|c|c|c|c|c|c|c|c|}
\hline \multirow[t]{2}{*}{ No. } & \multirow[t]{2}{*}{ City } & \multirow[t]{2}{*}{ Country } & \multicolumn{2}{|c|}{$\begin{array}{l}\text { Air pollution } \\
\text { parameters- } \\
\text { annual mean } \\
\left(\mu \mathrm{g} \mathrm{m}^{-3}\right)\end{array}$} & \multicolumn{2}{|c|}{ Data as on 2 July 2020} & \multirow[t]{2}{*}{$\begin{array}{l}\text { Percentage mortality per } \\
\text { reported COVID19 cases } \\
(\text { death/cases } \times 100)\end{array}$} \\
\hline & & & $\mathrm{PM}_{2.5}$ & $\mathrm{PM}_{10}$ & Reported cases & Reported deaths & \\
\hline 1 & Delhi & India & 143 & 292 & 89,802 & 2803 & 3.121 \\
\hline 2 & Nagpur & India & 84 & 86 & 1582 & 15 & 0.948 \\
\hline 3 & Kanpur & India & 173 & 319 & 1207 & 52 & 4.308 \\
\hline 4 & Islamabad & Pakistan & 66 & 217 & 13,195 & 129 & 1.053 \\
\hline 5 & Lahore & Pakistan & 68 & 198 & 39,512 & 705 & 1.784 \\
\hline 6 & Jakarta & Indonesia & 45 & 59 & 11,823 & 638 & 5.396 \\
\hline 7 & Tianjin & China & 69 & 103 & 198 & 3 & 1.667 \\
\hline 8 & Guilin & China & 47 & 64 & 98 & 1 & 1.020 \\
\hline 9 & Hebei & China & 73 & 128 & 349 & 6 & 1.719 \\
\hline
\end{tabular}




$$
Y=m X+C+\varepsilon
$$

where $Y$ is the response variable, $m$ is the slope, $X$ is the model input variable, $C$ is the model constant or the intercept, and $\varepsilon$ is the model error. The model regression coefficients, $m$ and $C$, are computed using the least square method by minimising the sum of squared residuals (Montgomery et al. 2012; Bower 2000; Raj et al. 2019). The model variable $X$ is assumed to be normally distributed with equality of variance for every observation. In the present analysis, the term $X$ (i.e. air pollution parameters) is modelled using the logarithmic transformation, which makes a reduction in the skewness of the data set. The model error term $(\varepsilon)$ is the difference between the actual response and predicted response, which is computed using the best-fit regression model. The error term is assumed to have zero mean and is uncorrelated (Montgomery et al. 2012).

Analysis of variance on the regression model is performed to quantify the strength of the relation of air pollution parameter on the response variable, which is depicted by the $R^{2}$ value. All the analysis and computation are performed at a confidence interval (CI) of $95 \%$ using Minitab 14 (Minitab Inc., 2003).

\section{Results}

The linear regression model on the response variable is fitted with respect to the two air pollution parameters, $\mathrm{PM}_{2.5}$ and $\mathrm{PM}_{10}$. Table 2 depicts the regression model coefficients and associated standard errors (SE) for the regression coefficients. It is observed that $\mathrm{PM}_{2.5}$ has the significant impact on the response variable, i.e. percentage mortality per reported COVID-19 cases $(p<0.05$ at $\mathrm{CI}$ : $95 \%)$; however, $\mathrm{PM}_{10}$ does not show any significant impact of the response with $p=0.118$. It is observed that the mortality rate is positively correlated with both the air pollution parameters, as PM can act as a carrier to transport the coronavirus aerosols, suspended in air and water media, into the respiratory tract of the humans and transmitting infections.

The analysis of variance on the regression model is given in Table 3. From the table, it can be inferred that the percentage mortality per reported COVID-19 cases is correlated significantly with $\mathrm{PM}_{2.5}\left(R^{2}=50.1 \%\right.$ and $\left.R^{2} \mathrm{Adj}=42.9 \%\right)$ than with $\mathrm{PM}_{10}\left(R^{2}=31.2 \%\right.$ and $R^{2} \mathrm{Adj}=24.1 \%$ ). Given the limited data set, it is not recommended to predict the mortality rate based on the developed regression model.

Figure 1 represents the best fit line plot for the model parameters with the 95\% CI. Also, due to limited data points and absence of replicates, lack of fit test based on pure error could not be performed. It can be seen from Fig. 1 that $\mathrm{PM}_{2.5}$ has closely distributed to

Table 2 Linear regression models for a percentage of mortality per reported COVID19 case

\begin{tabular}{lclcl}
\hline Predictors & Coefficient & SE Coef & $T$ & $P$ \\
\hline $\mathrm{PM}_{2.5}\left(\mu \mathrm{g} \mathrm{m}^{-3}\right)$ & & & & \\
Constant & -8.518 & 4.116 & -2.07 & 0.077 \\
$\log _{10}\left(\mathrm{PM}_{2.5}\right)$ & 5.747 & 2.169 & 2.65 & 0.033 \\
$\mathrm{PM}_{10}\left(\mu \mathrm{g} \mathrm{m}^{-3}\right)$ & & & & \\
$\mathrm{Constant}$ & -4.56 & 3.899 & -1.17 & 0.281 \\
$\log _{10}\left(\mathrm{PM}_{10}\right)$ & 3.226 & 1.811 & 1.78 & 0.118 \\
\hline
\end{tabular}


Table 3 Analysis of variance (ANOVA) for the linear regression model

\begin{tabular}{llllll}
\hline Source & DF & SS & MS & F & P \\
\hline $\mathrm{PM}_{2.5}$ & & & & \\
Regression & 1 & 10.167 & 10.167 & 7.02 & 0.033 \\
Residual error & 7 & 10.139 & 1.448 & & \\
$S=1.20350$ Press $=$ & 17.1597 & $R^{2}=50.1 \%$ & $R^{2}(\operatorname{adj})=42.9 \%$ & \\
PM $_{10}$ & & & & \\
Regression & 1 & 6.333 & 6.333 & 3.17 & 0.118 \\
Residual error & 7 & 13.973 & 1.996 & & \\
$S=1.41283$ Press $=22.7084$ & $R^{2}=31.2 \%$ & $R^{2}(\operatorname{adj})=21.4 \%$ & \\
\hline
\end{tabular}

$\mathrm{PM}_{2.5}$ $\mathrm{PM}_{10}$

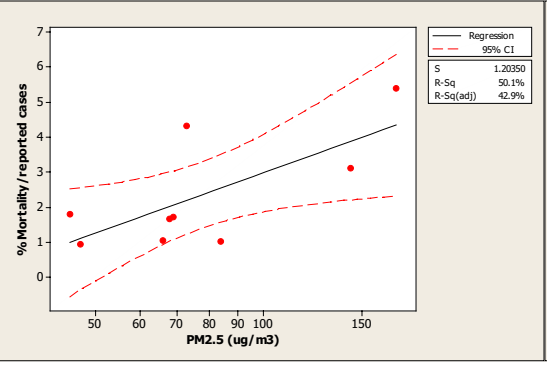

(a)

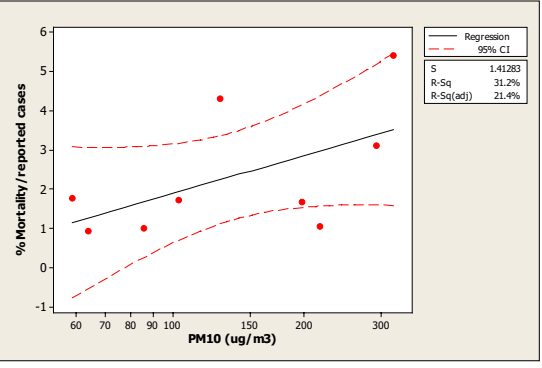

(b)

Fig. 1 Linear regression fitted line plots for $\mathbf{a} \mathrm{PM}_{2.5}$ and $\mathbf{b} \mathrm{PM}_{10}$

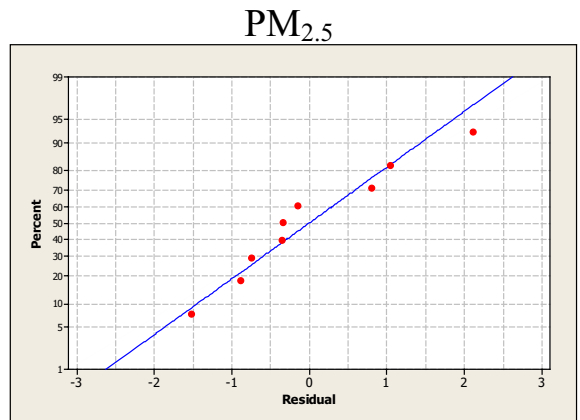

(a)

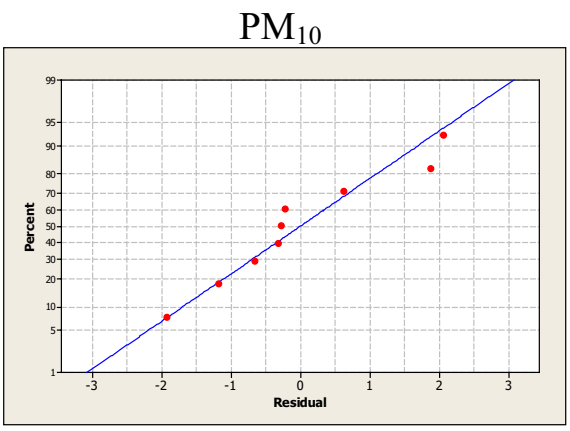

(b)

Fig. 2 Normal probability plot depicting residual for a $\mathrm{PM}_{2.5}$ and $\mathbf{b} \mathrm{PM}_{10}$

the best fit line (CI 95\%) as compared to $\mathrm{PM}_{10}$. The results are consistent with the fact that $\mathrm{PM}_{2.5}$ is respirable, and these particles can enter into the lungs and directly impact human health. The model error (or residuals) is shown in Fig. 2 through a normal probability plot. The residuals are in close agreement with the normal distribution line, which confirms the 
above fact stated with reference to Fig. 1 and that the model adequacy and hence the equality of variance at modelled observation hold true.

The counter-plot for the percentage mortality per unit reported cases is depicted in Fig. 2. From the contour-plot, it can be observed that the low level of pollution will aid in reducing the mortality rate among reported COVID-19 cases. However, the contour is skewed towards the $y$-axis: $\mathrm{PM}_{2.5}$, indicating a higher impact of the $\mathrm{PM}_{2.5}$ parameters on mortality rate than that of $\mathrm{PM}_{10}$. It is important to note here that $\mathrm{PM}_{2.5}$ impacts more on the human body as it infiltrates within the human body as compared to the restrictive pathway of larger $\mathrm{PM}_{10}$ particle. The correlation also supports that $\mathrm{PM}_{2.5}$ is better correlated with the response factor, proving that air pollution is positively affecting the mortality of COVID-19 cases (Fig. 3).

\section{Discussion}

Air pollution exposure beyond the prescribed limits has always been harmful to humans and the ecosystem at large. Right from minor respiratory problems to deadly diseases like cancers, air pollution is one of the major drivers of mortality globally. The air pollution data for the select cities depicted the $\mathrm{PM}_{2.5}$ and $\mathrm{PM}_{10}$ concentrations multifold higher than the WHO guideline values. The nine cities of Asia have been investigated in relation to COVID-19 reported mortalities. In view of the examined statistical observations, within the framework of the available data sets, it can be inferred that there exists a relationship between expsoure to high level of air pollutant in a region, over long time periods and increased reported deaths related to COVID-19. With the established correlations, it can be inferred that continuous exposure to undesirably high pollutant concentration must have impacted the immune system of the regional population. This is further supported by the fact that percentage mortality per unit reported COVID-19 case is significantly correlated with $\mathrm{PM}_{2.5}(p<0.05)$, which is responsible for most of the air pollution-related deaths around the world and have a profound impact in comparison with $\mathrm{PM}_{10}$.

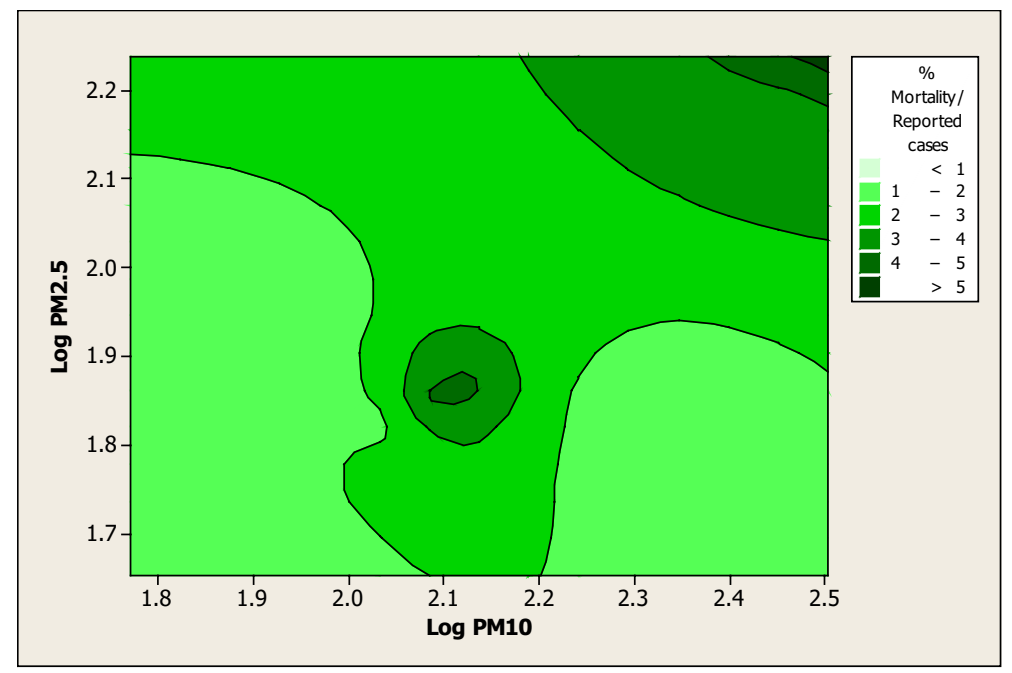

Fig. 3 Contour plot for the percentage of mortality per unit reported cases with respect to $\mathrm{PM}_{2.5}$ and $\mathrm{PM}_{10}$ 
Given the results, it can be concluded that air pollution is acting as a hidden element in exasperating the impact of COVID-19. In view of COVID-19 mortality rate associated with the air pollution, it becomes essentially important that people residing in cities with a higher level of air pollution should be more vigilant and take necessary steps to boost up their immune system, to avoid falling prey to this hidden cause of mortality. This poses a challenge to the already struggling health care systems of the respective countries affected by COVID-19. There is a necessity to identify the hot pockets of air pollution-affected cities and add layered protection in terms of boosting the immunity of the individuals. The findings of the study can help in guiding the health ministries of respective nations around the world to provide additional safety guidelines for highly polluted cities and prescribe immunity-boosting medicines. In India, the Ministry of AYUSH suggests Homeopathic and Unani medicines for boosting the immunity of the people which is a welcoming step in this direction. Furthermore, the use of mask may also cut down the exposure to SARS-CoV-2, given that the virus-carrying aerosols are in the range of $1-5 \mu \mathrm{m}$ range. Therefore, the use of mask, especially catering to $\mathrm{PM}_{2.5}$ or below, becomes critical in such highly polluted cities to reduce the impact of air pollution, thereby reducing the risk associated with COVID-19.

Theoretically, on the basis of the above research, the analysis should hold true for cities of developed countries as well; however, developing countries have special challenges when it comes to fighting COVID-19. A vital aspect is the living standards of developing countries. As these countries are already facing challenges on their livelihood front, adapting to the new enemy of COVID-19 becomes additional stress. The Information-Education-Communication (IEC) about the preventive measures, to mitigate the spread of the virus, to the remotest parts, is taxing and faces ground-level implementation and monitoring challenges. Effective IEC, through right stakeholders' engagement, encouraging socially distanced public participation, may prove beneficial and pave the way in mitigating the virus spread, faced by these countries.

Acknowledgements Authors thankfully acknowledge Council of Scientific and Industrial Research (CSIR), India, and its constituent laboratory National Environmental Engineering Research Institute (NEERI) for supporting the research. The authors further acknowledge the support from Karunya Institute of Technology to support the research. The manuscript is checked for plagiarism using licensed iThenticate software wide CSIR-NEERI Knowledge Resource Centre [KRC], CSIR- CSIR-NEERI/KRC/2020/APRIL/CSUM-DRCDIR/2 on 26th April 2020.

Data availability The data used in the manuscript are publicly available: 1 . Wikipedia, List of most polluted cities by particulate matter concentration: (URL-01) https://en.wikipedia.org/wiki/List_of_most-pollu ted_cities_by_particulate_matter_concentration. 2. Delhi coronavirus cases and deaths: (URL-02) https:// news.google.com/covid19/map?hl=en-IN\&mid=/m/09f07\&gl=IN\&ceid=IN:en. 3. Guilin, Hebei, Tianjin Corona cases and death (URL-03) https://www.statista.com/statistics/1090007/china-confirmed-andsuspected-wuhan-coronavirus-cases-region/. 4. Lahore corona cases and death (URL-04) https://www. geo.tv/latest/284205-coronavirus-updates-april-22-latest-news-on-the-covid-19-pandemic-from-pakistanand-around-the-world. 5. Kanpur corona cases and death (URL-05) https://www.covid19india.org/state/ UP. 6. Nagpur corona cases and deaths (URL-06) https://www.covid19india.org/state/MH. 7. Islamabad: https://covid.gov.pk/stats/ict. 8. Jakarta: https://news.google.com/covid19/map?hl=en-IN\&mid=/g/11x9y $3 z j 2 \& g l=I N \&$ ceid $=I N$ :en.

\section{References}

Anenberg, S. C., Achakulwisut, P., Brauer, M., Moran, D., Apte, J. S., \& Henze, D. K. (2019). Particulate matter-attributable mortality and relationships with carbon dioxide in 250 urban areas worldwide. Scientific Reports, 9(1), 1-6. 
Balakrishnan, K., Dey, S., Gupta, T., Dhaliwal, R. S., Brauer, M., Cohen, A. J., et al. (2019). The impact of air pollution on deaths, disease burden, and life expectancy across the states of India: The Global Burden of Disease Study 2017. The Lancet Planetary Health, 3(1), e26-e39.

Bherwani, H., Nair, M., Musugu, K., Gautam, S., Gupta, A., Kapley, A., et al. (2020a). Valuation of air pollution externalities: comparative assessment of economic damage and emission reduction under COVID-19 lockdown. Air Quality, Atmosphere and Health, 13, 683-694. https://doi.org/10.1007/ s11869-020-00845-3.

Bherwani, H., Gupta, A., Anjum, S., Anshul, A., \& Kumar, R. (2020). Exploring dependence of COVID-19 on environmental factors and spread prediction in India. Research Square. https://doi. org/10.21203/rs.3.rs-25644/v1.

Bower, K. M. (2000). Analysis of variance (ANOVA) using MINITAB. Scientific Computing and Instrumentation, 17, 64-65.

Cascella, M., Rajnik, M., Cuomo, A., Dulebohn, S. C. \& Di Napoli, R. (2020). Features, evaluation and treatment coronavirus (COVID-19). In Statpearls [internet]. StatPearls Publishing.

CBS News. (2017). The most polluted cities in the world. Retrieved 3, Feb 2017, from https://www. cbsnews.com/pictures/the-most-polluted-cities-in-the-world-ranked/.

Cohen, A. J., Brauer, M., Burnett, R., Anderson, H. R., Frostad, J., Estep, K., et al. (2017). Estimates and 25-year trends of the global burden of disease attributable to ambient air pollution: An analysis of data from the Global Burden of Diseases Study 2015. The Lancet, 389(10082), 1907-1918.

Dutheil, F., Baker, J. S., \& Navel, V. (2020). COVID-19 as a factor influencing air pollution? Environmental Pollution (Barking, Essex: 1987), 263, 114466.

D’Amato, G., Baena-Cagnani, C. E., Cecchi, L., Annesi-Maesano, I., Nunes, C., Ansotegui, I., et al. (2013). Climate change, air pollution and extreme events leading to increasing prevalence of allergic respiratory diseases. Multidisciplinary Respiratory Medicine, 8(1), 12.

Fenger, J. (1999). Urban air quality. Atmospheric Environment, 33(29), 4877-4900.

Gautam, S. (2020a). The influence of COVID-19 on air quality in India: A boon or inutile. Bulletin of Environmental Contamination and Toxicology. https://doi.org/10.1007/s00128-020-02877-y.

Gautam, S. (2020b). COVID-19: Air pollution remains low as people stay at home. Air Quality Atmosphere and Health. https://doi.org/10.1007/s11869-020-00842-6.

Gautam, S., \& Hens, L. (2020a). SARS-CoV-2 pandemic in India: what might we expect? Environmental Development and Sustainability, 22, 3867-3869.

Gautam, S., \& Hens, L. (2020b). COVID-19: Impact by and on the environment, health and economy. Environment, Development and Sustainability. https://doi.org/10.1007/s10668-020-00818-7.

Gautam, S., \& Trivedi, U. K. (2020). Global implication of bioaerosol in pandemic. Environmental Development and Sustainability, 22, 3861-3865.

Ghorani-Azam, A., Riahi-Zanjani, B., \& Balali-Mood, M. (2016). Effects of air pollution on human health and practical measures for prevention in Iran. Journal of Research in Medical Sciences, 21, 65.

Gupta, A., Mulukutla, A. N., Gautam, S., TaneKhan, W., Waghmare, S. S., \& Labhasetwar, N. K. (2020). Development of a practical evaluation approach of a typical biomass cookstove. Environmental Technology and Innovation, 17, 100613.

Gurjar, B. R., Ravindra, K., \& Nagpure, A. S. (2016). Air pollution trends over Indian megacities and their local-to-global implications. Atmospheric Environment, 142, 475-495.

Kim, D., Chen, Z., Zhou, L. F., \& Huang, S. X. (2018). Air pollutants and early origins of respiratory diseases. Chronic Diseases and Translational Medicine, 4(2), 75-94.

Lee, A., Kinney, P., Chillrud, S., \& Jack, D. (2015). A systematic review of innate immunomodulatory effects of household air pollution secondary to the burning of biomass fuels. Annals of Global Health, 81(3), 368-374. https://doi.org/10.1016/j.aogh.2015.08.006.

Li, T., Hu, R., Chen, Z., Li, Q., Huang, S., Zhu, Z., et al. (2018). Fine particulate matter $\left(\mathrm{PM}_{2.5}\right)$ : The culprit for chronic lung diseases in China. Chronic Diseases and Translational Medicine, 4(3), 176186.

Minitab, I. (2003). Minitab statistical software, release 14 for windows. State College, PA: Windows.

Mishra, V. (2003). Indoor air pollution from biomass combustion and acute respiratory illness in preschool age children in Zimbabwe. International Journal of Epidemiology, 32(5), 847-853.

Montgomery, D. C., Peck, E. A., \& Vining, G. G. (2012). Introduction to linear regression analysis (Vol. 821). Hoboken: Wiley.

Nair, M., Bherwani, H., Kumar, S., Gulia, S., Goyal, S. K., \& Kumar, R. (2020). Assessment of contribution of agricultural residue burning on air quality of Delhi using remote sensing and modelling tools. Atmospheric Environment, 230, 117504. https://doi.org/10.1016/j.atmosenv.2020.117504.

Pawankar, R. (2019). Climate change, air pollution, and biodiversity in Asia Pacific: impact on allergic diseases. Asia Pacific Allergy, 9(2), e11. https://doi.org/10.5415/apallergy.2019.9.e11. 
Raj, I., Gupta, A., Pandharipande, S. L., Bansiwal, A., \& Vaidya, A. N. (2019). A high performance biological degradation of trimethylamine: Experimental study and mathematical modeling. Journal of Environmental Chemical Engineering, 7(5), 103292.

Rom, W. N., Boushey, H., \& Caplan, A. (2013). Experimental human exposure to air pollutants is essential to understand adverse health effects. American Journal of Respiratory Cell and Molecular Biology, 49(5), 691-696.

Shamsipour, M., Hassanvand, M. S., Gohari, K., Yunesian, M., Fotouhi, A., Naddafi, K., et al. (2019). National and sub-national exposure to ambient fine particulate matter $\left(\mathrm{PM}_{2.5}\right)$ and its attributable burden of disease in Iran from 1990 to 2016. Environmental Pollution, 255, 113173.

Tong, S. (2019). Air pollution and disease burden. The Lancet Planetary Health, 3(2), e49-e50.

Torrey, B. B. (2004). Urbanisation: An environmental force to be reckoned with. Washington, DC: Population Reference Bureau.

United Nations Population Division (UNPD). (2018). World urbanization prospects: The 2018 Revision.

Wang, C., Horby, P. W., Hayden, F. G., \& Gao, G. F. (2020). A novel coronavirus outbreak of global health concern. The Lancet, 395(10223), 470-473.

Wang, P., Chen, K., Zhu, S., Wang, P., \& Zhang, H. (2020). Severe air pollution events not avoided by reduced anthropogenic activities during COVID-19 outbreak. Resources, Conservation and Recycling, $158,104814$.

World Health Organization (WHO). (2006). WHO Air quality guidelines for particulate matter, ozone, nitrogen dioxide and sulfur dioxide: Global update 2005: Summary of risk assessment (No. WHO/ SDE/PHE/OEH/06.02). Geneva: World Health Organization.

World Health Organisation (WHO) (2018a). WHO household air pollution and health: Global update 2018. Retrieved April 20, 2020 from https://www.who.int/news-room/fact-sheets/detail/household-air-pollu tion-and-health.

World Health Organisation (WHO) (2018b). WHO air pollution, ambient air pollution: health impacts. Retrieved April 20, 2020 from https://www.who.int/airpollution/ambient/health-impacts/en/.

World Health Organization (WHO). (2018c). Ambient air pollution-a major threat to health and climate. Copenhagen: World Health Organization.

World Health Organization (WHO). (2018d). WHO global ambient air quality database (update 2018). Geneva: World Health Organization.

World Health Organization (WHO) (2020a). Coronavirus disease 2019 (COVID-19): Situation report, 72.

World Health Organization (WHO) (2020b). Coronavirus disease (COVID-19) advice for the public.

Xing, Y. F., Xu, Y. H., Shi, M. H., \& Lian, Y. X. (2016). The impact of $\mathrm{PM}_{2.5}$ on the human respiratory system. Journal of Thoracic Disease, 8(1), e69.

Publisher's Note Springer Nature remains neutral with regard to jurisdictional claims in published maps and institutional affiliations. 